\title{
Influence of microfabric evolution on the retention behaviour of compacted clayey soils
}

\author{
A.C. Dieudonné \\ University of Liege, Liege, Belgium \\ F.R.I.A., Fond de la Recherche Scientifique - FNRS, Brussels, Belgium \\ G. Della Vecchia \\ Politecnico di Milano, Milano, Italy \\ R. Charlier \\ University of Liege, Liege, Belgium \\ C. Jommi \\ Delft University of Technology, Delft, Netherlands
}

\begin{abstract}
After compaction, clayey soils exhibit an evident bimodal pore size density function (PSD). The two classes of pores are usually addressed as intra-aggregate and inter-aggregate porosity: these structural levels interact each other and show different behaviours along hydro-mechanical paths. In this paper selected experimental data of pore size density function, obtained by mercury intrusion porosimetry tests on different clayey soils are analysed and modelled by means of van Genuchten analytical expression. Different evolution patterns for PSD parameters are identified for intra- and inter-aggregate pores. The consequences on the water retention properties are analysed by means of a simple double structure retention model, which links pore size to suction through Laplace equation. The model is able to explicitly take into account the influence of water content and void ratio changes on the pore size evolution of the two structural levels. As a consequence, the specific hydro-mechanical paths induced by water retention testing can be followed and the influence of void ratio variation and of the applied stress can be predicted. Water retention data collected during a specific test are thus interpreted and modelled as the envelope of different water retention states, each of them corresponding to a specific fabric. The water retention model is finally validated against experimental data.
\end{abstract}

\section{INTRODUCTION}

Compacted clayey soils are used in a wide range of geotechnical and geo-environmental applications. In civil engineering, compacted clays are found in embankments and earth dams, whereas they are considered as engineered barriers for the disposal of domestic, industrial and hazardous waste. In these applications, the compacted material remains essentially unsaturated over its service life. The characterization of its water retention properties is thus fundamental to a comprehensive understanding and modelling of the coupled response of the material in terms of water flow and deformation processes.

Since many years, numerous studies have recognised the importance of the material microstructure on the engineered properties of compacted clayey soils (see Romero 2013 for a review). While compacted dry side of optimum, clayey soils exhibit a typical aggregated fabric. This fabric is not unique and the size of the aggregates appears to be sensitive to the compaction water content (Thom et al. 2007), the chemical composition of the interstitial fluid (Musso et al. 2013) and the particular hydromechanical path followed (Delage, 2010). Further- more, the structure is not fixed but evolves along stress-paths (see for instance Romero et al. 1999, Cuisinier \& Laloui 2004, Della Vecchia 2009, Monroy et al. 2010, Wang et al. 2012).

The development of a water retention model for compacted clays should thus ideally take into account the evolving aggregated character of the soil. In the last years, increasing attention has been paid to the links between the water retention properties of a soil and its evolving pore size distribution (Simms \& Yanful 2002, Romero et al. 2011, Casini et al. 2012, Beckett \& Augarde 2013, Della Vecchia et al. 2013, Hu et al. 2013).

In this paper, a water retention model for compacted clayey clays is proposed. The model takes into account the aggregated structure of the material as it is directly linked to its pore size density function through Laplace equation. Experimental data on compacted Boom clay are used to calibrate and later validate the model. Finally the model is used to track microstructural changes along various hydromechanical stress paths. 


\section{A WATER RETENTION MODEL LINKED TO THE PORE SIZE DENSITY FUNCTION}

\subsection{Model formulation}

The water retention model proposed by Romero et al. (2011) and Della Vecchia et al. (2013) has been conceived to take into account microfabric evolution along hydro-mechanical paths. The structure of the model is such that for high suction values (i.e $s>s_{m}$, where $s_{m}$ is the suction corresponding to saturated aggregates and empty macropores) water fills only the intra-aggregate pores and the retention mechanism is independent from the mechanical state. On the other hand, for suction lower than $s_{m}$, water starts to fill the inter-aggregate voids: in this case a storage mechanism dominates, leading to a water retention response sensitive to void ratio variations. According to the approach of Romero et al. (2011), the information retrieved from the PSD curves was used to calibrate the evolution law for the intra-aggregate porosity as a function of water content, linking the subdivision between micro- and macro-pores to a discriminating pore diameter $d_{m}$ : all the pores whose size is larger than $d_{m}$ belong to inter-aggregate pores, viceversa they fall in the intra-aggregate category. The discriminating diameter was suggested to correspond to the peak of the unimodal PSD distribution obtained saturating an as-compacted sample at constant volume. Figure 1 shows the determination of the discriminating diameter for compacted Boom clay, as well as the subdivision between macro-pores and micro-pores for the as compacted sample.

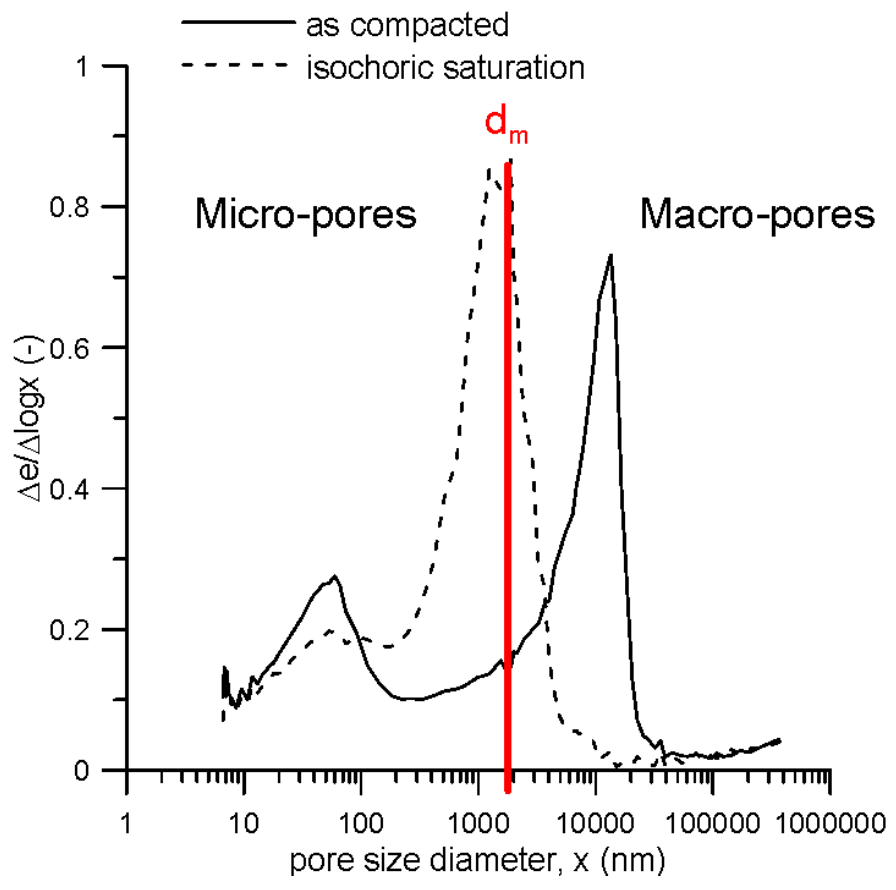

Figure 1. Pore size density functions of as-compact and isochoric saturated Boom clay. Micro- and macro-porosity are distinguished on the basis of the fixed diameter $d_{m}$.

The model presented in the present work follows a different approach, being the double-porosity nature of compacted clays introduced explicitly: two elementary retention mechanisms, one for each domain, are defined on the whole suction range, without the need of any discriminating diameter. The retention domain of each structural level is defined by a simple van Genuchten equation (Dieudonnè et al., 2013). The water ratio $e_{w}$ (volume of water $V_{w}$ over the volume of solids $V_{s}$ ) is split into the water ratio of the micro-structure $e_{w m}$ (volume of water in the micropores over the volume of solids) and the water ratio of the macro-structure $e_{w M}$ (volume of water in the micropores over the volume of solids):

$$
\begin{aligned}
& e_{w}=e_{w m}+e_{w M}=e_{m}\left[1+\left(\alpha_{m} s\right)_{m}\right]^{-m_{m}}+ \\
& +\left(e-e_{m}\right)\left[1+\left(\alpha_{M} s\right)^{n} M\right]^{-m_{M}}
\end{aligned}
$$

where $s$ is suction, $e$ and $e_{m}$ are the global and microstructural void ratio, $\alpha$ is a parameter linked to the air-entry value and $n$ and $m$ are two model parameters. Subscripts $m$ and $M$ represent micro- and macro-structure, respectively. In this equation, the residual water ratio has been assumed equal to zero. Indeed the stress was put on the suction range corresponding to engineering applications of compacted clays.

Using Laplace equation to link suction to the equivalent pore diameter $R$ (under the assumption of soil pores modelled as a bundle of cylindrical tubes), it is possible to link the water retention curve to the corresponding pore size density function, PSD. For the sake of simplicity, the formalism is here introduced with reference to a mono-modal porous medium, i.e. characterized by a single structural level and thus by a single retention mechanism. The extension to multi-modal distributions is straightforward. The link between the cumulative pore size distribution $F(R)$, the pore size probability function $f(R)$ and the retention curve expressed in terms of degree of saturation $\operatorname{Sr}(s)$ is simply

$$
F(R)=\int_{R_{\min }}^{R} f(r) d r=\operatorname{Sr}(s)
$$

The pore size density function, PSD, can be obtained by the relation

$$
P S D=\frac{d e}{d \log (r)}=e \cdot f(R) \cdot R \cdot \ln (10)
$$

It is evident that a variation of parameters $\alpha, m$ and $n$ implies both a variation in the retention properties of the material and an evolution the pore size distribution.

\subsection{Model calibration}

The PSD model has been calibrated for compacted Boom clay on the basis of mercury intrusion porosimetry data presented in Della Vecchia (2009). 
All the sample were prepared statically compacting Boom clay powder at the dry density of $\rho_{d}=13.7$ $\mathrm{Mg} / \mathrm{m}^{3}$ and at two different water contents, $w=15 \%$ and $w=19 \%$, and then subjected to different hydromechanical paths. The evolution law of aggregate size with water content has been introduced through an equation similar to the one proposed in Romero et al. (2011):

$$
e_{m}=\beta_{0} e_{w}^{2}+\beta_{1} e_{w}+e_{m, 0}
$$

where $\beta_{0}$ and $\beta_{1}$ are two parameters quantifying aggregate swelling and $e_{m 0}$ is the intra-aggregate void ratio for the dry material. The values assumed for compacted Boom clay are $\beta_{0}=0.2, \beta_{1}=0.05$ and $e_{m 0}=0.33$. Figure 2 shows some of the experimental data used for the calibration procedure, which evidence the effects on the PSD of wetting paths performed with different mechanical constraints, starting from the as-compacted condition (sample BCC2, $e_{0}=0.97, e_{w 0}=0.38, s_{0}=2000 \mathrm{kPa}$ ). Sample BCC4 has been subjected to constant volume saturation, while samples BCC25 and BCC26 were subjected to wetting in oedometer at constant vertical stress, 85 $\mathrm{kPa}$ and $600 \mathrm{kPa}$, respectively. Model predictions as a consequence of the calibration procedure are presented in Figure 3. Calibration has been performed directly on the PSD data, trying to keep fixed the greatest number of parameters as possible and trying to correlate the varying parameters with hydromechanical state variables. Since mercury is not able to intrude the smallest pores of the material (i.e. the pores with the size below $6 \mathrm{~nm}$ for maximum applied pressure $220 \mathrm{MPa}$ ), the macrostructural domain has been calibrated first. The microstructural void ratio $e_{m}$ is thus expressed as the difference between the total void ratio and the macrostructural one. The calibration procedure has shown that some parameters can be considered as constant (i.e. $n_{m}$, $\left.m_{m}, m_{M}\right)$, while others show a significant dependence on material state (see Dieudonné et al. (2013) for further details). The subdivision of micro-pores and macro-pores corresponding for the as-compacted sample is shown in Figure 4: no discriminating diameters have been used, so that a superimposition zone is present. In the framework proposed, it is thus possible that two pores of a given size belong to different domains.

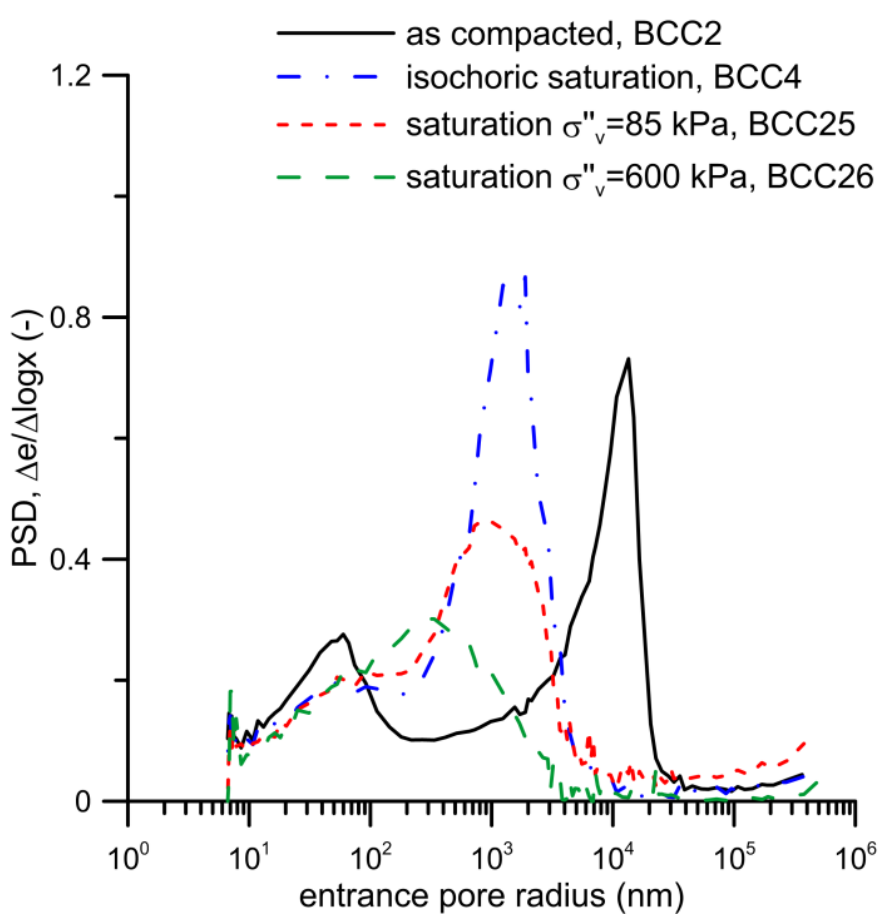

Figure 2. Pore size density function for Boom clay samples subject to wetting under different mechanical constraints: experimental data.

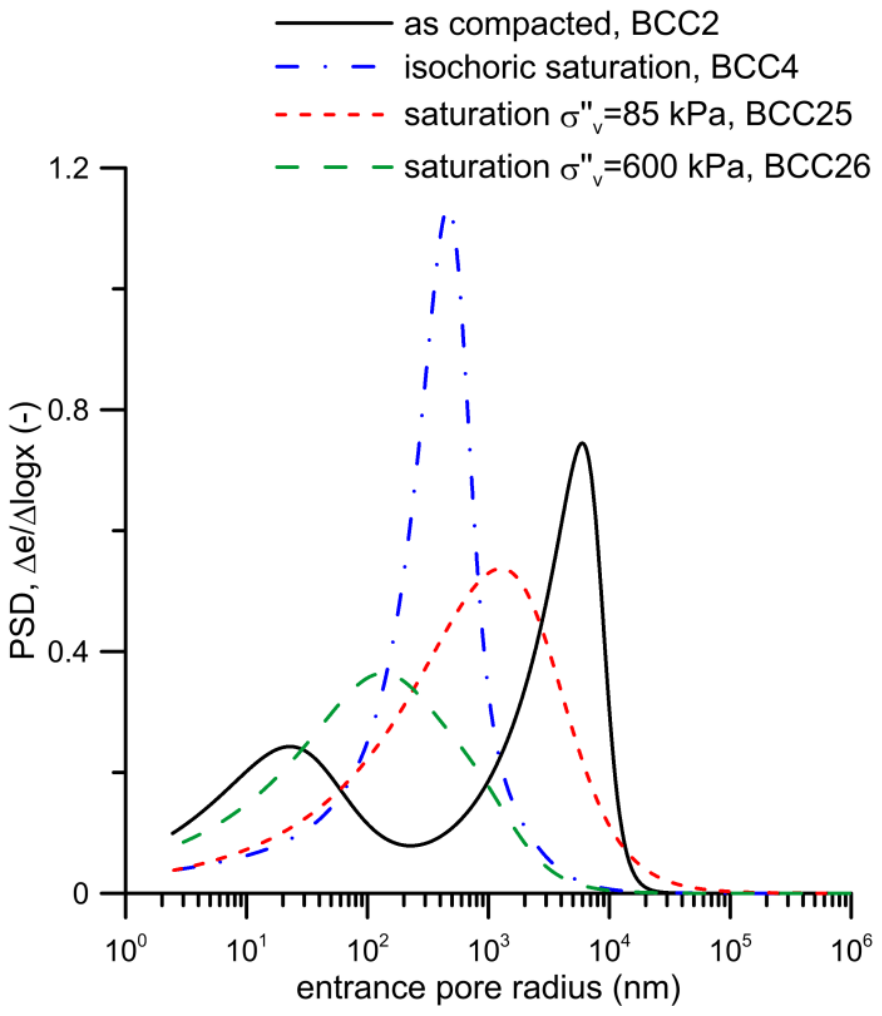

Figure 3. Pore size density function for Boom clay samples subject to wetting under different mechanical constraints: model calibration. 


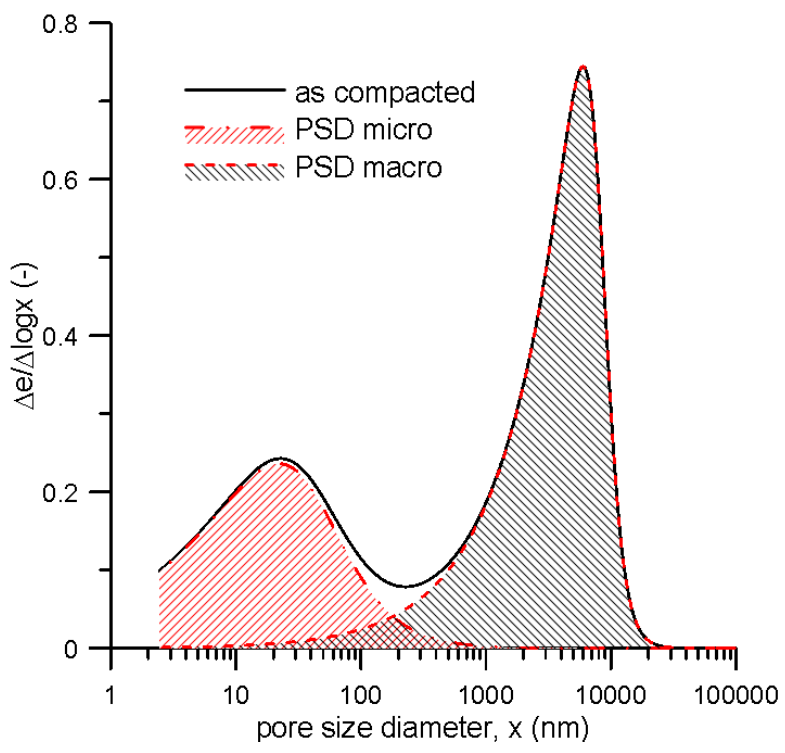

Figure 4. Pore size density function for as compacted Boom clay: subdivision between micro and macro domains

\section{MODEL VALIDATION AND PREDICTIONS}

Water retention data presented in Romero et al. (2011) has been used to validate the water retention curve obtained calibrating the parameters on porosimetry data. Due to the fact that a mercury intrusion path is performed introducing in the dry porous medium a non-wetting fluid (i.e. mercury) with respect to air, numerical values obtained from PSD data are considered belonging to the drying branch of the water retention curve.

Figure 5 shows the predicted retention curve for compacted Boom clay, with reference to two constant void ratios, $e=0.63$ and $e=0.92$. The simulation has been performed keeping fixed the parameters $n_{m}=1.65, m_{m}=0.35, n_{M}=2$ and $m_{M}=0.16$, and varying $1 / \alpha_{m}$ and $1 / \alpha_{M}$ according to the evolution laws obtained during the calibration phase:

$$
\begin{gathered}
\frac{1}{\alpha_{m}}=a_{1}^{(m)} \exp \left(-a_{2}^{(m)} \cdot e_{m}\right) \\
\frac{1}{\alpha_{M}}=a_{1}^{(M)} \exp \left(-a_{2}^{(M)} \cdot\left(\frac{e-e_{m}}{e}\right)\right)
\end{gathered}
$$

with $a_{1}{ }^{(m)}=180 \mathrm{MPa}, a_{2}^{(m)}=9, a_{1}{ }^{(M)}=1.5 \mathrm{MPa}$ and $a_{2}{ }^{(M)}=5$. The model is able to properly simulate the reduction of the air entry value for increasing void ratio, as well as the reduction of the influence of void ratio for increasing suction. Being calibrated on a huge number of hydro-mechanical paths, the model can be fruitfully used also to predict the hydraulic response of the material along different hydromechanical paths.

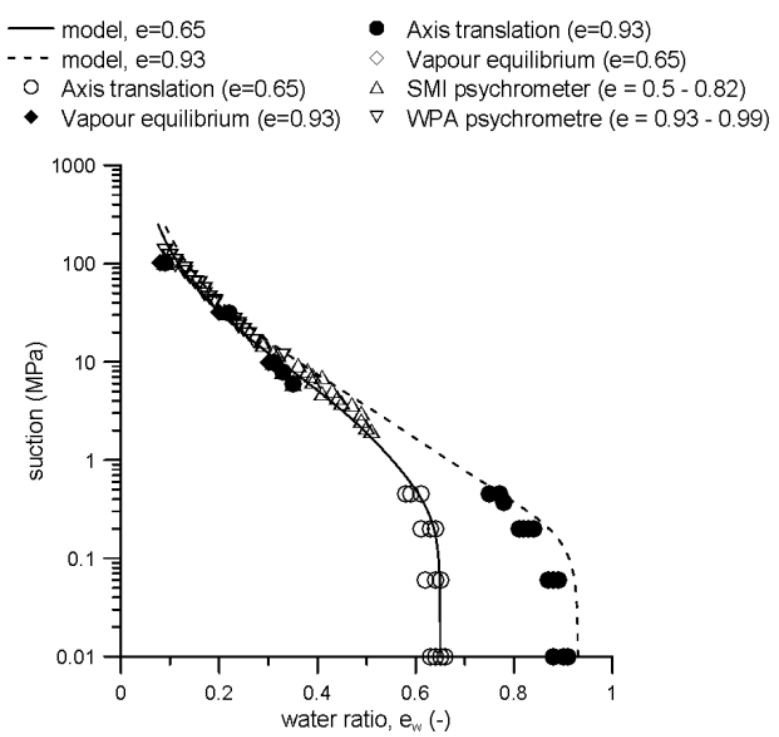

Figure 5. Water retention curve for compacted Boom clay: drying branch.

Experimental results from an isotropic suction controlled wetting-drying-wetting path at constant net pressure $p$ "' (presented by Romero (1999)) are shown in Figure 6, in terms of void ratio and water ratio evolution against suction. Void ratio - suction data have been used as an input for the water retention model, and the water ratio exchanged by the sample has been simulated, as shown in Figure 6. To simulate the main wetting curve of the material, only the parameters $a_{1}^{(m)}$ and $a_{1}^{(M)}$ have been changed with respect to the ones used for the drying curve.

The model proved able to follow the evolution of water ratio, not only during the first wetting path, but also along the following drying-wetting cycle.

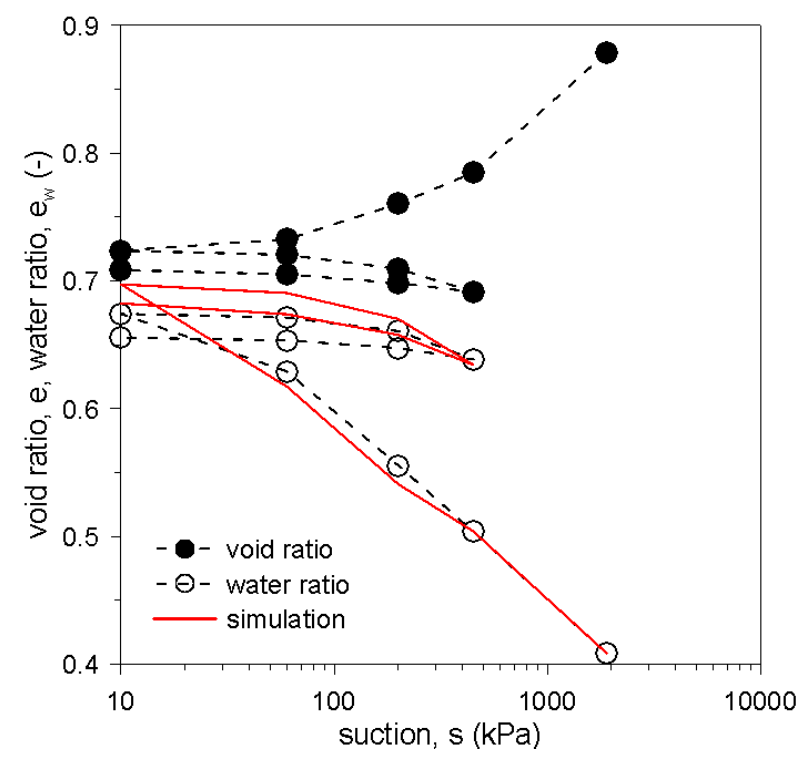

Figure 6. Constant p" isotropic test on compacted Boom clay: experimental data and model prediction.

Another useful application of a validated water retention model that is able to follow microstructural evolution of the material along different paths is the possibility to estimate suction variation during test 
where suction cannot be measured neither imposed. Figure 7 shows experimental data coming from the two swelling tests performed at different vertical net stress introduced in section 2 (BCC25 and BCC26 samples). Samples were loaded in oedometer at constant water content up to a vertical net stress of 85 $\mathrm{kPa}$ (BCC25) and $600 \mathrm{kPa}$ (BCC26). Afterwards, they have been subjected to a water content controlled wetting at constant vertical stress. During wetting, only axial displacement and water inflow were measured (Figure 7)

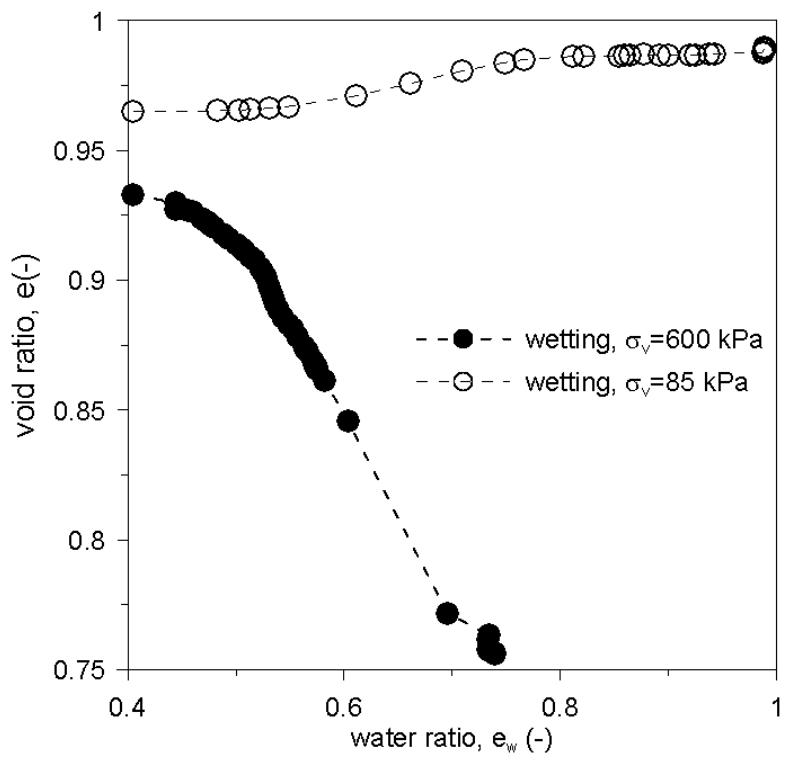

Figure 7. Void ratio evolution during controlled water content wetting test performed in oedometer at different constant vertical stress.

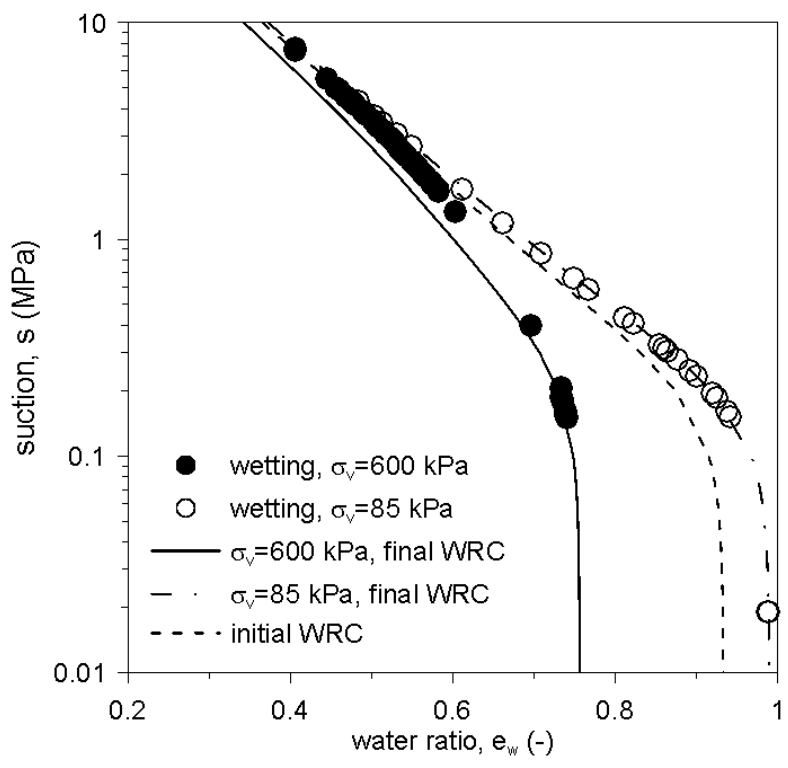

Figure 8 . Water retention curves before and after wetting paths at different applied vertical stress.

The predicted values of suction during the two wetting paths are shown in Figure 8 (symbols), together with the predicted initial water retention curve (ascompacted material, 'initial WRC' in the legend) and the retention curves corresponding to the fabric of the material after swelling upon wetting $\left(\sigma_{\mathrm{v}}=85\right.$ $\mathrm{kPa})$ and collapse upon wetting $\left(\sigma_{\mathrm{v}}=600 \mathrm{kPa}\right)$. Starting from the same as-compacted condition (i.e. the same fabric), the hydro-mechanical paths diverges in the $s-e_{w}$ plane, leading to different fabric and thus different water retention properties.

\section{CONCLUSIONS}

A water retention model accounting for the evolution of the aggregated structure of compacted clays along generalized hydromechanical stress paths is presented. In this model, intra- and inter-aggregates water retention mechanisms are described separately using an expression of the type proposed by van Genuchten. Using Laplace equation, a pore size density function is derived. Selected experimental data of pore size distribution on compacted clay are analysed and reinterpreted in the eyes of the proposed model. Different evolution patterns for PSD parameters are identified for microstructural and macrostructural pores. The consequences of the microfabric evolution on the water retention properties are then highlighted and analysed in details. The PSD model is able to explicitly take into account for the influence of water content and void ratio changes. Validation of the water retention model against experimental data is presented. Specific hydromechanical paths induced by water retention testing can be followed and the influence of void ratio variation and of the applied stress can be predicted.

\section{REFERENCES}

Beckett, C.T.S \& Augarde, C.E. 2013, Prediction of soil water retention properties using pore-size distribution and porosity, Canadian Geotechnical Journal 50: 435-450.

Casini, F., Vaunat, J., Romero, E. \& Desideri, A. 2012. Consequences on water retention properties of double-porosity features in a compacted silt. Acta Geotechnica 7: 139-150.

Cuisinier, O. \& Laloui, L. 2004, Fabric evolution during hydromechanical loading of a compacted silt, International Journal for Numerical and Analytical Methods in Geomechanics 28 (6): 483-499.

Delage, P. 2010. A microstructure approach to the sensitivity and compressibility of some eastern Canada sensitive clays, Géotechnique 60(5): 353-368.

Della Vecchia 2009.Coupled hydro-mechanical behaviour of compacted clayey soils. Politecnico di Milano, Phd thesis.

Della Vecchia, G., Jommi, C. \& Romero, E. 2013, A fully coupled elastic-plastic hydro-mechanical model for compacted soils accounting for clay activity, International Journal for Numerical and Analytical Methods in Geomechanics 37(5):503-535.

Dieudonné, A.C., Levasseur, S., Charlier, R., Della Vecchia, G., Jommi, C. 2013. A water retention model for compacted soils. In S. Pietruszczack and G.N. Pande (eds.), Computational Geomechanics COMGEO III, Proc. of the 2rd Inter- 
national Symposium on Computational Geomechanics, Krakow, Poland: 23-31. Rhodes \& Swansea: International Centre for Computational Engineering.

Hu, R., Chen, Y.F., Liu, H.H. \& Zhou, C.B. 2013, A water retention curve and unsaturated hydraulic conductivity model for deformable soils: consideration on the change in poresize distribution, Géotechnique, on line, http://dx.doi.org/10.1680/geot.12.P.182.

Monroy, R., Zdravkovic, L. \& Ridley, A. 2010. Evolution of microstructure in compacted London Clay during wetting and loading. Géotechnique 60 (2): 105-119.

Musso, G., E. Romero, G. Della Vecchia, 2013, Double structure effects on the chemo-hydro-mechanical behaviour of compacted active clay. Géotechnique 63 (3): 206-220.

Romero, E. 1999. Thermo-hydro-mechanical behaviour of unsaturated Boom clay: an experimental study. Universitat Politècnica de Catalunya, Phd thesis.

Romero, E., Gens, A. \& Lloret, A. 1999. Water permeability, water retention and microstructure of unsaturated compacted Boom clay, Engineering Geology 54(1): 117-127.

Romero, E, Della Vecchia, G. \& Jommi, C. 2011, An insight into the water retention properties of compacted clayey soils, Géotechnique 61(4): 313-328.

Romero, E. 2013, A microstructural insight into compacted clayey soils and their hydraulic properties, Engineering $\mathrm{Ge}$ ology 165: 3-19.

Simms, P.H. \& Yanful, E.K. 2002, Predicting soil-water characteristic curves of compacted plastic soils from measured pore-size distributions, Géotechnique 52 (4): 269-278.

Thom, R., Sivakumar, R., Sivakumar, V., Murray, E.J., Mackinnon, P. 2007, Pore size distribution of unsaturated compacted kaolin: the initial states and final states following saturation. Géotechnique 57(5): 469-474.

Wang, Q., Cui, Y.-J., Tang, A.M., Barnichon, J.D., Saba, S., Ye \& W.-M., 2013, Hydraulic conductivity and microstructure changes of compacted bentonite/sand mixture during hydration, Engineering Geology 164: 67-76. 